\title{
Adapting and Modernizing the Post-Covid Marketing Policy Under the Impact of Consumption Challenges
}

\begin{abstract}
Victor Danciu ${ }^{1}$
Abstract

The turmoil created by the COVID-19 pandemic in all components of the society has effects that become challenging for people and companies. This scientific approach aims at drawing attention primarily to the new trends in consumption and consumer behavior. The main trends identified are the reduction of expenses, the priority given to basic needs satisfaction, the changes of the structure of the consumer basket, the increasing digitalization, the increase of home delivery, the reorientation towards local shopping, the omnichannel services and increasing of the importance of the green content.

The transformation, enrichment and improvement of marketing and especially of the marketing policy in accordance with the change of consumption is another objective of the research. Achieving these objectives will depend on the digital marketing practices and strategies and tactics of product, communication, distribution and price adapted to the new realities.
\end{abstract}

Keywords: COVID-19, consumption, consumer behavior, marketing policy, marketing digitalization

JEL Classifications: M21, M31, M37

DOI: $10.24818 / \mathrm{REJ} / 2021 / 79 / 01$

\section{Introduction}

The action and effects of COVID-19 pandemic generate changes in all parts of the social, economic and technologic life, health and wellbeing. These trends have created different threats that make consumer primarily concerned about the adverse effects on consumption and life in the present and probably the future.

The purpose of the research is to highlight how these concerns support new trends in consumption and in consumer behavior. A survey conducted by Numerator Intelligence (US) in 2020 on consumer concerns about coronavirus founds that they are questioning its most significant adverse effects as in Table 1.

\footnotetext{
${ }^{1}$ Professor, The Bucharest University of Economic Studies, e-mail: dvictorsambotin@yahoo.com Year XXIV no. 79 March 2021
} 
Their impact changes consumption and consumer behavior as shown in the following inventory (Kohli S. et al, 2020; Mc Kinsey, 2020):

- Work: increasing unemployment, remote working, on-to-go consumption declines.

- Life at home: nesting at home, surge in online.

- Learning: education online.

- Health and wellbeing: focus on hygiene, acceleration of organic, natural, fresh, fitness on demand, e-pharmacy, e-doctor at scale.

- Communication and information: in-person sampling decline, shift in media consumption.

- Shopping and consumption: surge in e-commerce, preference of trusted brands, decline in discretionary spending, trading down, reduced shopping frequency, shift in store closer to home, increasing green and sustainability solutions.

- Travel and mobility: reduction on tourist spending and travel retail, increase in domestic tourism and entertainment: preference for digital entertainment, entertainment channel shift e.g. cinema to streaming, additional play time.

Table 1. Main consumer concerns regarding COVID_19

\begin{tabular}{|l|c|}
\hline \multicolumn{1}{|c|}{ Consumer concerns } & Percentage (\%) \\
\hline Impact on the economy & 59 \\
Danger of personal / family infection & 57 \\
Impossibility to buy to meet daily needs & 43 \\
Confined to the home & 36 \\
Cancellation of travel & 34 \\
Impossibility to buy other goods and services & 30 \\
Impact on job security & 26 \\
\hline
\end{tabular}

Source: 11/25 Update: Numerator.com/resources. blog, 2020

Starting from this picture of the main changes in consumption and consumer behavior, our research aims to analyze the most unique ones and with the greatest input. The results are used for the reorientation and refreshing of the marketing policy. Then, the priorities of consumers are highlighted. They must be found in marketing policy solutions adapted to new realities which are flexibility, empathy, value for money, communication and distribution based on advanced digitization and prices that better meet the consumer requirements. 


\section{New trends in consumption and consumer behavior}

Consumption driving changes. The population is afraid of the effects of coronavirus on society in general. The range of reactions is relatively wide, extensive. The research of Accenture in the midst of the pandemic in April 2020 showed that consumers fear more about the consequences of COVID-19 on the economy. Thus, $88 \%$ of those surveyed said they fear the effects of coronavirus on the economy, while $64 \%$ fear for their own health (COVID-19: How consumer behavior will be changed, accenture.com, April 28, 2020). But health concerns are also rising, as further research on stress suggests. The results show that where the virus remains aggressive, $86 \%$ of consumers are concerned about health while $65 \%$ have the same reaction in areas where the impact of the coronavirus begins to stabilize. The impact of COVID-19 on job security concerns 65\% of consumers (COVID-19 is Reshaping the Consumer Goods Industry, June, 2020, accenture.com).

As consumers, people are afraid to frequent public spaces for both social and commercial purposes. Going to stores and pharmacies was seen as acceptable by $45 \%$ by mid-2020 but participation in sporting events or concerts was acceptable for only $19 \%$ and in bars and clubs for $18 \%$ in the US. These circumstances created by coronavirus bring to the top of the consequences some long-term trends regarding consumers.

Orientation towards meeting basic needs is the priority trend. Consumers are becoming more aware of the costs in terms of declining incomes and job uncertainties. The research shows that people agree to spend more only justifiably, respectively $54 \%$ in May 2020, while only $28 \%$ will buy more and $4 \%$ will reduce their expenses. Moreover, the economic recession and the high unemployment rate have made consumers stop spending easily, extra and reduce household expenses and even reduce the list of essential goods in order to ensure financial security.

Conscious consumption has a growing trend, which translates into increased attention to what one buys, attempts to limit food waste, greater awareness of procurement costs and the purchase of more sustainable solutions (Coronavirus has accentuated three long-term trends, 2020, accenture.com).

Focus on health is growing dramatically with consumers, shoppers and employees sharing a growing concern to stay healthy. The consequences of this orientation are found in the increase for hygiene and cleaning products that ensure medical safety, in general, and personal safety, in families and friends.

Year XXIV no. 79

March 2021 
Consumer behavior changes according to the new reality. The COVID-19 pandemic has caused new buying and consuming habits and behaviors to take on new characteristics. The most obvious change is the descent in the hierarchy of needs to the basic ones, such as food, security and safety. Changes and bans on time management have resulted in changes in shopping habits in online shopping, delivery at home or the transformation of leisure habits. In the sense of changing habits one may specify the new rules of work, such as wearing a mask and keeping a social distance or the time allowed to leave the house. These, and also lockdown and travel restrictions, have changed the choice of place for shopping and consumption too. Working, schooling and shopping all have shifted and localized at home (Jagdish S., 2020). Also, time management is more flexible because it is not always done according to exact plans for school, shopping or consumption.

All these elements and the way they act on acquisitions and consumption give rise to a wide range of changes and novelties of specific behavior. Their importance and consequences are discussed in the literature and research to capture or confirm them in practice. Trends and confirmations regarding changes in buying and consuming behavior are studied and tested by many entities. The articles and points of view deal with the specific problem of the changes in consumption behavior caused by the pandemic all over the world. These include Hoekstra el al, Kholi et al, Rogers K. et al, Haller K. et al, Wade et al and many others. Many points of view based on sociological researches are expressed by the World Economic Forum, KPMG, McKinsey, Ernst \& Young, Boston Consulting Group, J.P. Morgan Nielsen but also Kantar, Accenture or Numerator Intelligence.

The findings and the issued points of view allow the inclusion of consumer behavior changes determined by the impact of the pandemic in a seven point list (BC1-BC7).

BC1: Changing the structure of the shopping basket and expenses. In general, lowering revenues and rising uncertainties about the future make their mark on buying and consuming behavior. Especially retirees or those who retire during this period, small business owners and those with very low incomes are the ones who spend less.

Consumers in all countries spend more on basic necessities than before the pandemic, which reduces the costs of other less essential categories. Staying at home for longer periods increases the importance of cooking and eating at home. The research conducted by Numerator Intelligence, periodically updated, shows in the version from November 23, 2020 - that the ways in which Americans eat 
and shop have changed drastically. Thus, $56 \%$ eat and drink at home more often, $60 \%$ go to restaurants and bars less or not at all (18\%). In the future, $26 \%$ say they will continue to eat and drink more often at home (11/25 Update, Numerator, 2020). In the UK, research conducted by You Gov and the Food Foundation in April 2020 found that 19 million people were cooking more at home in mid-2020 and 17 million were throwing away less food (oneplanetwork.org, July 29, 2020). Data released by Euromonitor International shows that food and household products are on the rise and also hygiene and wellness products, digital products, gardening materials, furniture and electronics (Hoekstra et al, 2020, p. 251).

CB2: Increasing digitization of the purchasing process. The phenomenon of digitalization in purchasing and consumption and marketing activities existed before the appearance of the coronavirus. The crisis induced by the effects of the pandemic, including restrictions, has changed normal behavior around the world. It had a special impact on the digital component of the purchasing and consumption, especially because of the closure of many stores and the obligation of consumers to stay at home. As a result, the use of digital channels has grown rapidly and continuously. A survey conducted by KPMG International, the results of which were published in November 2020, found that of the $43 \%$ of the customers who previously preferred person-to-person contacts, 33\% switched to using digital channels. The percentage of those using face-to-face channels has dropped from $43 \%$ before coronavirus to $23 \%$ in mid-2020, while digital channels increased from $26 \%$ to $44 \%$ and the use of digitally enabled contact channels i.e. apps, social media, email, messenger apps increased by $6 \%$ compared to the increase of websites by $4 \%$. Digital channels will remain the main contact in the future, supporting 45\% more customers (KPMG, November, 2020, p. 14).

Information on online shopping was obtained through a survey conducted by UNCTAD, entitled "COVID-19 and ecommerce" on a sample of people from China, Germany, Italy, Republic of Korea, the Russian Federation, South Africa, Switzerland and Turkey. More than half of the respondents said they buy online more often. By product groups and activities, the survey shows that online purchases increased by $6 \%$ to $10 \%$ in most categories. The largest increases were in ICT / Electronics (10\%), gardening and do-it-yourself (9\%), pharma / health $(9 \%)$, education $(8 \%)$, furniture and household products $(7 \%)$ and cosmetics and personal care $(7 \%)$ (unctad.org.org, October 08, 2020). A survey conducted in early May 2020 by Go Group and Kameleoon in the US, UK, Germany, France and Italy found that $54 \%$ of the consumers tend to listen more to streaming entertainment, $47 \%$ to read more the press, $33 \%$ to take online classes and $27 \%$ to buy products to improve home gardens. Taking into account the previous results and the increasing trend of the use of digital channels post-COVID, it can be 
stated that e-commerce is the winning channel of the COVID-19 crisis. Euromonitor has conducted worldwide research showing that online shopping will become permanent. Thus, over 55\% state that they will continue to buy online permanently in the retail network, approximately $55 \%$ will purchase foodservice and approximately 48\% travel services (A. Tudor, October 5, 2020).

CB3: Higher and more deliveries at home. The COVID-19 pandemic has forced many people to reevaluate many of their habits, including the ways in which they access goods. The fear of infection, staying at home and working from home, as well as various restrictions, made them reduce the number of contacts, sometimes to zero. One of the most visible consequences is the accelerated growth of home deliveries as a result of the self-protective behavior of the customers. The strongest forces that press in the sense of resorting to home deliveries are their advantages. Using home delivery made closeness to people, the items purchased are probably touched by fewer people, there is no need to use a mean of transport and even payment can be made contactless. An important and sensitive advantage is the possibility of higher incomes. The amplification of the advantages that lead to the increase of home deliveries can be obtained if specific innovations are brought in. Some examples can show what new advantages can be obtained with the help of innovations. To protect home deliveries, a smart technology system called eDOR has been created and used with the function of protection against theft of packages. Another innovation is the use of drones for home delivery. UPS began delivering packaged goods using drones in 2019 and in 2020 joined forces with Wingcopter, the German company, to build a fleet of drones for regular deliveries. Today, Wingcopter electric drones cover an area of 120 kilometers, with a speed of 240 kilometers per hour (Top 7 home delivery innovations, springwise.com).

BC4: Reorientation towards local shopping. The increase in the inclination for local shopping is seen both in speeding up the preferences for products and brands and for local sources. The research conducted by Accenture in mid-2020 shows that $59 \%$ of consumers wanted to buy more local products from nearby stores (Accenture, June 2020). In Romania, research conducted by GfK Consumer Panel \& Services in the first quarter of 2020 and Ernst \& Young online between May 13th and June 2nd highlighted trends in consumer behavior when buying groceries that are summarized in Table 2.

Table 2. Behavior changes of Romanian consumers

\begin{tabular}{|c|l|}
\hline Behavior constituent part & \multicolumn{1}{c|}{ Tendency } \\
\hline Brands & $\begin{array}{l}\text { Private labels gained ground ahead of national brands and } \\
\text { cover } 21 \% \text { of total sales }\end{array}$ \\
\hline
\end{tabular}

Year XXIV no. 79

March 2021 


\begin{tabular}{|c|l|}
\hline Behavior constituent part & \multicolumn{1}{c|}{ Tendency } \\
\hline Place of shopping & $\begin{array}{l}\text { Romanians return to nearby stores; small shops and } \\
\text { discount stores had the larger increases }\end{array}$ \\
\hline Product type & $\begin{array}{l}\text { Migration toward local products to the detriment of } \\
\text { imported ones }\end{array}$ \\
\hline Need of digitization & $\begin{array}{l}\text { E-commerce poorly represented, less than 1\% of total } \\
\text { sales }\end{array}$ \\
\hline & Source: Stratila A., 2020, p. 27
\end{tabular}

The orientation toward local brands, products and distribution sources offers companies new opportunities, especially those that produce and sell local consumer goods. Manufacturers and traders need to connect locally. They need to stimulate closer relationships with smaller local shops and collaborate with them to provide customers with locally sourced products, tailored to local needs and preferences. The purpose of such behavior is to persuade customers to buy local goods and return to trade in small units, an approach that is not easy to achieve due to the vigilance and strengths of the large commercial networks.

BC5: Migration of consumers to private labels, promotions and more substantial discounts. The conditions created by the effects of the pandemic have pressured traders to reduce their promotions and discounts in stores. As a result, consumers have begun to migrate to private labels, i.e. retailer brands, more substantial promotions and discounts. Information that confirms these trends and the extent of the consumer sphere is made public by various entities that have researched the phenomenon. Ernst \& Young periodically publishes Index of Behavior and Assortment. Data published by country shortly after mid-2020 on changes in consumer preferences for private labels show that their magnitude is significant for all product categories and geographically (ey.com, August 07, 2020). Even if private labels have a large increase in consumer preferences, the trend will continue. For example, 67\% of UK consumers will consider buying private labels from the food group in the future compared to the current market share of $37 \%$.

In the case of some products and countries, the difference between the propensity to buy and the potential sales of private labels is quite large. For instance, $41 \%$ of American consumers say they are considering purchasing a private label product in the beauty and personal category, while its market share is only 4\%. Regardless of the product category, the highest availability to buy private labels is in relation to the "affordability" the highest percentage recorded by packaged foods (Rogers K.; Cosgrove A., 2020). 
BC6: Omnichannel services: One of the dynamic changes in consumer behavior during the pandemic is the increasing use of omnichannel services. The omnichannel is a multichannel sales approach that provides the customer with an integrated customer experience (Fontannella C., 2020). The seamless experience is providing weather the customer is shopping online from a mobile device, a laptop or in a brick-and-mortar store (Robert T., 2020). This means that the same consumers use online and offline channels that form a specific mix of buying behavior. Omnichannel service differs from multichannel because unlike the last one it connects to all channels.

The more accentuated orientation towards the use of multichannel is dictated by the difficulties created by the pandemic, but this alternative offers significant advantages that surpass various conjunctures. In a synthetic-explanatory approach, the defining benefits of omnichannel commerce are the following (Fontanella C., 2020; Robert T., 2020).

Omnichannel commerce offers better customer experience. It facilitates the integration of all touch points with the help of social adds, email newsletters, mobile push notifications, conversion with chat-bots or face-to-face chat with the store staff.

Omnichannel commerce brings increases in sales and traffic. Customers who use omnichannel spend more money in the store for purchases. Customers who use more than four channels spend an average of $9 \%$ more in the store, compared to the one who uses a single channel (Robert T., 2020).

Omnichannel commerce boosted customer loyalty. In the six months since the start of omnichannel shopping, 23\% of customers have visited retail stores more often. More people who turn to omnichannel are more willing to recommend the product they buy to family and friends who use a single channel. Focusing on customer loyalty allows retailers to make less effort for discount, mid-sales campaigns and other marketing procedures (Robert T., 2020).

Omnichannel commerce allows better data collection. Merchants who manage to identify and track customers' travel on all channels used can serve them better, giving them a much better personalized experience.

CB7: Increasing importance of the green content of the purchasing decision. The eco, green, environmental component occupies an increasingly significant place in the buying and consuming behavior and the pandemic consolidates this trend. The green ingredients and properties of the products, their impact on the environment and 
the consumption of resources but also the origin of the consumed products gain an increased importance in the purchasing decisions. Concerns for environmental protection are transformed into knowledge in the case of green consumers, which has a favorable effect on the attitude and decision to buy green products. Controversy over the origin of COVID-19 only strengthens customers' willingness to buy and consume green products. A survey conducted by Kearney in the US highlights how the buying behavior of green products adapts to the situation created by the pandemic. Thus, $48 \%$ of the respondents said that the pandemic made them more concerned about the environment and 55\% that they are more willing to buy environmentally friendly products (Kearney, April 22, 2020). Worldwide, a research in 28 countries has found that consumers seek to buy brands and products that are clean (78\%), environmentally responsible $(77 \%)$, recycable $(76 \%)$ and use natural ingredients $(72 \%)$ (Haller and Lee, 2020). A significant example is the sales of electrical products that are environmentally responsible. Worldwide, they increased 2.2 times in the period 2010-2019 and by $90 \%$ in 2019-2020 compared to the previous period (telegraph.co/u k/searchmarketing).

\section{New approaches of adapting and modernizing the marketing policy}

The accelerated digitalization of processes and activities appropriate to marketing policy. The coronavirus pandemic has a strong impact on the digitalization of marketing. Digital practices in various components of the marketing mix have expanded and will continue to strengthen their participation in the transformation, enrichment and improvement of marketing. Digital marketing is stimulated by the advantages it offers. A first advantage consists in facilitating the access to any necessary information about companies, markets, consumer, branded products, services, and practices. Then, digital communication makes much easier a closer relationship of consumers with the companies and their products but also knowledge of markets and virtual customers by the companies. The use of digital solutions allows the identification of several options from which consumers can choose. The number of options is facilitated by the access to the generous offer in depth and breath. The offer of certain products such as electronics, personal care, pet supplies and groceries is 80 times higher than that provided by traditional stores and multichannel retailers (Belaiche J. M.; Chassaing T.; Kapadia S., 2012). A significant benefit of digitization is the time spent in the process of buying and consuming. Buyers are informed faster and can choose the fastest solution for the purchase. The use of digital channels facilitates savings by those involved in actions on the market. Lower costs and increased competition for the same items increase the dynamics of prices, with repeated and

Year XXIV no. 79

March 2021 
substantial discounts. Merchants gain access to new markets and customers at reasonable costs. They can sell directly and thus eliminate the costs of intermediaries. Also, with the communication and sales platforms expenses, as well as of the services are not too high.

Digitalization of marketing has the effect of changing consumer behavior during the pandemic and many innovations will be maintained later. They migrate to ecommerce, thus experiencing a new way of buying. Merchants must reconsider their approach to customers. Using information about online shoppers, they should target advertisers to their target customers who are familiar with the product rather than attracting new customers from others.

The most necessary to benefit movement for digitalization is innovation, but the one that will allow companies to better adapt to post-COVID realities. Potential innovations can be found in the range of means and techniques that can be used to digitalize marketing, which are systematized in the following solutions (OBrien H., aumcore.com December 24, 2020).

Shoppable posts. This solution is a response to the tendency of consumers to adopt the quickest and easiest option to buy. Different social media platforms that allow the purchase of an article with a single click can facilitate this option.

Voice search welcomes people who are looking for the easiest search to get news and various information. In order to be preferred in the search process, marketers must offer information with friendly and professional content.

Video marketing is an important and sensitive part of the marketers' communication strategies. Video content helps convince and attract customers, as people are more willing to communicate video than in writing or on the blog.

Chat bots meet the satisfaction of customer preferences for the existence of a "human touch". Powered by artificial intelligence, chat bots simulate human interaction, involving the customer more in the buying process. By changing the way the buying decision is made, the chat bots maintain and improve customer relationships. During the pandemic, online chat developed and increased the use of bots for marketing purposes. In France, a survey by HubSpot found that $45 \%$ of companies use bots for marketing purposes (Genilleau F., 2020). The growing trend of this innovation is to be maintained even after the coronavirus crisis, supported by the advantages offered by it, is to be expected.

Year XXIV no. 79

March 2021 
Artificial reality will gain a more important place in all digital marketing solutions, as it allows consumers to see products in 3D before making a purchase decision. The facility entails the possibility to buy in-person without traveling.

Virtual reality gives customers the opportunity to believe that they are shopping for in the shop, which satisfies the desire of many to act in a familiar environment.

Interactive content provides additional arguments for retailers' success in keeping their customers interested, demonstrating that they are creative and different from the competition. In the context of the growth of ecommerce, email marketing will differ depending on the situation of the companies. Companies that have done well such as groceries, e-tailors, digital entertainment providers, tech providers will focus on better customization, segmentation and automation. Airlines, hotels, cruise liners, traditional retailers and other companies that have been affected by coronavirus talk mainly to improve efficiency, obtain essential optimizations and perform analyzes and tests to adapt to changes in customer behavior (Dormer L., 2020).

Social messaging trends are the result of efforts that can be made to create networks that help reach the target audience at the same time as the targeted products and brands. This goal can be achieved with the help of certain social media platforms such as Facebook Messenger and Whatsapp.

Programmatic advertising aims to eliminate "gaps" in the process of planning the placement of advertising messages in the media so as to reach as many targeted recipients. Using this method, marketers can buy a real-time advertisement and place the messages in the desired places. Programmatic advertising facilitates spending budgets more efficiently, which can be a successful strategy.

An example of a company that has innovated in the field of digitalization is IKEA which uses augmented reality for online shopping in response to the closured of its stores.

The product policy. The effects of COVID-19 have made companies to reevaluate their product policy. The purpose of this approach is to counteract the loss of some customers, reduced revenues and decreased profitability. To succeed, companies must always evaluate their own offer at a pace that allows them to take appropriate action in each case. This means having adequate flexibility that can provide the market with a dynamic offer. Achieving this goal requires the company to constantly monitor, very carefully, the entire process of creation, 
production, marketing and post-marketing of each product, to have the information necessary to maintain and possibly improve the flexibility of the product policy, especially post-COVID.

The company can adopt and operationalize the right strategy if it chooses the most suitable alternative from those analyzed below.

The new products versus existing products strategy involves innovation and the development of new products for the competing market segment. Success is conditioned by innovating as fast as possible, where possible, as in healthcare, retail delivery service, digital service or communication offering. If the company does not have the opportunity or ability to innovate, it can extract value from existing product portfolio. Some of the options are price reevaluation, more easily accepted by the market, reevaluation of the increase of the value proposed by the price and individual or common packaging.

The same product and infrastructure strategy aims at associating the product with the existing infrastructure in an offer, so as to obtain a favorable effect (Wade, M., Bjerkan H., 2020). A first alternative of the strategy involves the use of the same products to be sold on at least one distribution channel different from the existing one (s). This may be the case for the same or a similar product that is offered to the online market, although it has been sold in the store until then. Practically all marketers resort to this option, from groceries to jewelry. Another alternative is to combine existing infrastructure with products different from the company's profile. Given the declining demand for many goods and services during the pandemic, often existing infrastructure is not used to its full capacity. The effects of coronavirus are found in the sub-capacity of factories, the lack of customers for hotels, bars and restaurants. At the same time, the pandemic has led to increased demand for other goods and services, such as masks or disinfectants. In order to use their own unused infrastructure, some companies quickly reoriented themselves to produce sanitizer as in the case of LVMH, Pernod Ricard, SKyroka. General Motors and Ford are among those that have modified certain production lines to produce electric fans, for example. Chains of hotels have made empty rooms available to medical workers and sometimes even coronavirus patients in countries like the United Kingdom. Amazon aims, by April 2020, at employing 100,000 people in the US, as a result of the increase in online purchases.

If the demand decreases, some employees can be retrained quickly, so as not to become unemployed. Scandinavian Airlines provided fast-track training to more than 1,000 former employees who had resigned to support the country's security 
system in the fight against coronavirus. In Germany, McDonald's employees were allowed to work temporarily in Aldis stores while its fast food restaurants were closed, and they could return to work once the fast food restaurants reopened.

Strategy of the eco, green, sustainable component. Since the COVID-19 crisis, attention to this component has increased and it is expected that more and more consumers will prefer green, eco, sustainable products after the pandemic. As a result, the environmental performance of companies will increase confidence in their products. In this context, the Green Consumption Pledge launched by the European Commission as part of the European Climate Pact initiated by the EU can also be discussed. L'Oreal is one of the pioneers committed to acting according to the EU Green Consumption Pledge. The company is committed to continuing efforts to reduce the carbon footprint of its new products and renovated products and will begin this process with shampoos in 2021. Other companies such as Decathlon, LEGO Group and Renewed have committed to do the same (European Commission, January 2021, ec. europa.en).

The communication policy. Consumer behavior is constantly changing and resetting and the coronavirus pandemic has accentuated this trend. New buying habits have emerged and other existing ones have changed. As a result, marketers must also make changes not only to goods and services but also to communication. They feel the need to capture new needs such as those regarding health, safety, freshness, new offers to eat and so on. Overall, merchants need to reconsider providing value for money and gain customer loyalty more than ever. All these requirements and also other ones change the communication policy. Thus, the first, the newest but also the one with the greatest impact consists in creating a relationship based on transparency between customers and brands, products and the company.

Customers have access to more and more different communication media and to the facilities offered by digitalization for information. Companies are turning into digital entities, too. Since the beginning of 2020, the digital transformation has become an accelerated process, marketing included. In this context, the digital advertising market has grown both in Europe and in other countries. In 2020, the digital advertising market reached 6066 million euros in France, which meant an increase of 3\% compared to 2019 (cbnnews.fr, June 24, 2020). In Romania, the value of the online advertising market exceeded 80 million in 2019, ranking among the top ten countries. The marketing communication is part of this process and is becoming significant, as companies increase their spending on email, chat bots, artificial intelligence apps, augmented and virtual reality. The consistent mix of 
devices that facilitate access to information and mobile communication represents the success of marketing. However, the content of the communication is the one that facilitates the achievement of success. To this end, communication must be based on the principle of transparency. This requires the company to provide clear and easily accessible information in the first place. In terms of the content, the information that is the subject of the communication must be complete, detailed and real, true. They must cover the range of products offered, their availability, the preferred distribution channels, the origin of the products, their ecological impact, to which social responsibility can be added.

The messages must contain clear, reasoned and easily accepted information by the clients, in the conditions in which they are more and more attentive to the aims pursued by the companies and their messages. In May 2020, about 64\% of the Internet users in Europe said that companies should run pandemic advertising campaigns. By country, the Internet users who strongly approve of the pandemic advertising campaigns were Italy (77\%), followed by Ireland (72\%), Spain (62\%), Poland (66\%), and Romania (63\%) (K. von Abrams; Ceurveles M., January 25, 2021).

The distribution policy. One of the serious challenges that the coronavirus pandemic creates for the companies is to find the most suitable ways to make it easier for the consumers to take possession of the purchased goods. The distribution situation has become sensitive as a result of exceeding the possibilities offered by brick-and-mortar in all categories, from boutiques to supermarkets and hypermarkets and beyond even to malls and restaurants. The closure of some distribution units for different periods of time, due to different restrictions, also contributed to the worsening of the situation. All these have contributed to the greater use of certain already existing distribution methods and channels and to the emergence of new ones. The evolution in their favor will continue postCOVID reflecting consumers' appetite for new experiences that will provide them much easier access to goods and services.

In a synthetic and enumerative approach, the future of the distribution policy is found in:

* The preferences of more and more buyers will continue in favor of digital distribution against the choice of direct channels, which will allow companies that adopt it to obtain advantages. They will be able to extend touchless delivery options to product receipt and service implementation, in addition to orders, information and payment.

Year XXIV no. 79

March 2021 
* Ecommerce will continue to gain ground which will require companies to increase their investments to meet the demands. The sales of total retails worldwide will be dependent on the ecommerce dynamic which is higher than the traditional one which decreased by $3 \%$ in 2020 compared to 2019 . By region, ecommerce sales evolved in 2020 as in Table 3. In 2021, the total retail worldwide will increase by $5.1 \%$, while ecommerce is likely by $14.3 \%$.

Table 3. 2020 Retail ecommerce sales, by regions

\begin{tabular}{|c|c|}
\hline Region & Ecommerce sales (\%) \\
\hline Latin America & 36.7 \\
\hline North America & 31.8 \\
\hline Central and East Europe & 29.1 \\
\hline Asia-Pacific & 26.4 \\
\hline Western Europe & 26.3 \\
\hline Middle East and Africa & 29.8 \\
\hline Worldwide & 27.6 \\
\hline
\end{tabular}

Source: e Marketer, December 2, 2020

* Home delivery will retain its position in all distribution methods. The advantages offered by the fact that it is a short and much more convenient channel are obtained more easily with the multiplication of the communication techniques.

In order for home delivery to matter more in all the distribution channels, it is necessary that many sales units meet all the conditions for complete and quality services. Steps to meet the required standards have been taken by several retail units since the beginning of the pandemic, in order to meet the increased demands of customers at a level similar to restaurants and other units that were already dealing with home delivery. All units that will deal with home delivery must use all means of communication from telephone and online to online platforms, especially those that take orders and deliver them to customers' homes and have the necessary staff to make these deliveries.

* Omnichannel distribution is an alternative used for over a decade but the interactions between the technologies used by the different component channels remained relatively weak until the advent of COVID-19. In 2019, only $30 \%$ of retailers could make online reservations for an item to be taken from the store, less than $15 \%$ offered an option to deliver in two hours or less, while $7 \%$ could offer customers the option to video chat support (Bourlier A., December 18, 2020). 
The coronavirus pandemic quickly changed the situation due to its effects, forcing traders to make the necessary efforts to bring the omnichannel option to the forefront. Euromonitor conducted a survey in July 2020 that confirmed this trend. The results of the survey show that many retailers expect to quickly increase investment in key components of the omnichannel alternative and attract third parties. Thus, $56 \%$ of respondents stated that the effects of coronavirus forced them to sell through digital channels. With the ability to combine all types of channels without restrictions, omnichannel includes brick-and-mortar stores, website, brand owned app but also marketplace presence, selling on social media partnering with last-mile delivery services (Bourlier A., 2020).

The price policy. The difficulties created by the crisis caused by coronavirus have also increased consumers' sensitivity to prices. Uncertainty about jobs, declining incomes, fear of the future were supplemented by original reasons that migrated to the top of the hierarchy and have the effect of conditioning the purchase decision. The uniqueness of the product and its importance to the consumer become more important, although they were already part of the mix of factors necessary for the purchase decision. More than ever, consumers are looking for products that deliver "value for money". Consumers' perception of the ratio between price and value became decisive for accepting or not the price of the product on the market. As a result, manufacturers are obliged to create products that meet this requirement, especially when it comes to well-known brands, and in terms of consumer perception of competing products.

At the strategic level, the main concern should be for product costs. The effects of COVID-19 are found in increased product spending, in many cases, which has the effect of lowering the profit margin and sometimes making the product unprofitable. The economic recovery will begin even if the coronavirus persists and it will probably act more quickly to improve the economic and social situation after the pandemic.

The price strategy will have to impose appropriate approaches to the market situation and its impact on the costs of each product (COVID-19-Impact on cost of products and services, pwc.be/en/new-publications/2020). Identifying changes in the effects of the pandemic on product costs is the first step that can have favorable effects. The changes will be able to be identified and researched after analyzing the information regarding the changes in the demand for the product, the changes in the structure of the direct costs and the unexpected reductions of the indirect costs. The results obtained as a result of the analysis performed will be used to review the company's product portfolio. For this review, data are also 
needed regarding the reconsideration of the demand for the product portfolio, the analysis of the impact of the changes in the demand in the allocation of costs and gross margin and the concentration on customer retention and the increase of the market share.

The information resulting from the identification of changes in costs and the revision of the portfolio are used in the stage of identification and analysis of the disadvantages registered in the company's product policy and of the advancement of the required solutions. First of all, it is necessary to identify products from the portfolio that have underperformed and over-performed, in the conditions of the changes registered by the demand in the pandemic and after it. Then, it is necessary to amend the changes in the existing price components, in order to feed the decision on changing the pricing policy in order to review the prices of the products in the portfolio and to identify the effects of these changes on the profit and possible losses. Subsequent decisions must be made on the basis of an analysis of the latest information and valid specific plans. For better substantiation it is necessary that the existing basic rules be reanalyzed in order to realistically allocate the costs necessary to ensure driver-based locations. Finally, the impact of final costs must be analyzed in order to make informed pricing decisions.

The substantiation of the price tactic that covers a short period of time and takes into account the circumstances aims at ensuring the most prompt reactions to the market sensitivity to the price in order to keep customers and determine others to focus on the company's products (Raymond J., 2020, p.254). The adaptation to fluctuations in demand and the pressures exerted on the prices of the company's products can be obtained if the variable costs such as those of transport and handling are replaced or changed. The acceptance of payments after the established deadlines and the multiplication of financing options can be included in the range of short-term measures that aim to stimulate customers' options in favor of the company's products. Lower or bundling prices can also be used in the short term to boost sales. They can be supplemented with temporary discounts if price sensitivity existed. All tactics must be used with care because they can lead to price wars.

\section{Conclusions}

The research provides clarifications on past changes in consumption and consumer behavior. First, are identified new trends that fit into the consumption theory, the theoretical arguments are backed up with information obtained from

Year XXIV no. 79

March 2021 
official sources, researches conducted by various entities and the views of the author.

The directions and ways in which the components of the marketing policy must be reevaluated, reset and reconstructed, as the case may be, in order to minimize the impact of the pandemic and getting post-COVID solutions are also analyzed. The more accelerated digitalization of marketing policy is argued in the context of the increasing digitalization of the purchasing and consumption process and of the progress already obtained and the pressures for a more sustained digitalization of the components of product, communication and distribution policy.

All this comes to support the substantiation of the correct answers that marketing can find to the problems created by the pandemic that align with the $3 \mathrm{R}$ strategic concept which is Respond, Reset, Renew.

\section{References}

Belaiche, J. M., Chassaing, T., Secrets of Online Marketplace, 2012-12-07, bcg.com Caizergues, G., 2020, L impact du COVID_19 sur le comportement des utilisateurs et le ecommerce, journal du net, Avril, 3, [online] Disponibil la journaldunet.com/solutions/seo-renforcement/ 1490231-I

DiResta, E.A.; Wilford, T.; Da Morus Cohen, A.; Gen, A.B., 2020, The impact of COVID-19 on your advertising and marketing campaigns, Holland \& Knight Allert, April 20, [online] Disponibil la hklaw.en/insights/ publications $/ 2020 / 04$

Dormer, L., 2020, Email marketing trends 2020, 13 January, [online] Disponibil la smartinsights.com/email-marketing/email-marketing-trends-2020/

Flood-Cramer, E., 2021, Global e-commerce Update 2021, January 13, [online] Disponibil la e-marketer.com

Fontanella, C., 2020, 15 examples of brands with brilliant omnichannel experiences, November 6, [online] Disponibil la blog.hubspot.com

Gentilleau, F., 2020, [Tribune] Le marketing reinvente: 5 changements post-covid, [online], Disponibil la e-marketing.fr/thematique/retail/1095/Brewes

Haller, K.; Lee Cheung, J., 2020, Meet the 2020 consumers driving change, IBM for Business Value

Hoekstra, J.; Leeflang, P., 2020, Marketing in the era of COVID-19, Italian Journal of Marketing, November 23, Issue 4, No 1, pp. 249-260

Itkoff, J., 2020, Marketing trends and effects from COVID-19, March 13, [online] Disponibil la avxdigital.com

Jagdish, S., 2020, Impact of COVID-19 on consumer behavior: Will the old habits return or die?, [online] Disponibil la ncbi.nlm.nih.gov/pme/articles/PMC769931/

Year XXIV no. 79

March 2021 
Jeff, R., 2020, The 4Ps of marketing amid COVID-19: Strategy reassessment and adjustment, April 27, [online] Disponibil la marketing.profs.com

Kent, L., 2020, COVID-19 changed consumer behavior and marketing strategy, Smart Brief, August 13, [online] Disponibil la smart-brief.com/original/2020/08

Kholi, S.; Tiwelin B.; Fabius, V.; Veranen, M.S., 2020, COVID-19 is changing how consumers behave across all spheres of life, McKinsey, [online] Disponibil la mckinsey.com/media industries/retail/our 20\% INSIGHTS/

Mehta, S.; Saxena,T.; Purohit, N., 2020, The new consumer behavior paradigm and COVID-19: Permanent or transient?, Journal of Health Management, July 30, [online] Disponibil la sage/pub/com/doi/

Obrien, H., 2020, 10 future digital marketing trends for 2021, December 24, [online] Disponibil la aumcore.com

Pollard, M.; O Neill C., 2020, How COVID-19 is impacting online food delivery platforms, April 30, [online] Disponibil la citivelocity.com

Rogers, K.; Cosgrove, A., 2020, The EY future consumer index of behavior and sentiment is tricking fundamental pivot away from brands to private label products, August 07, ey.com

Sarita, L., 2020, Adapt your marketing strategy for COVID-19, Gartner, March 17, [online] Disponibil la gartner.com/en/marketing/insights/articles

Short, M., 2020, Post-COVID predictions for the manufacturing and distribution industries, April 28, episerver.com

Stratila A., 2020, Convenience Stores in Romania. What has changed after COVID-19 outbreak?, International Conference of Economics and Social Sciences

Tam, B., 2020, How COVID-19 will change consumer behavior + purchase patterns, Hill \& Knowlton Strategies, April 27, [online] Disponibil la hkstrategies.com/en

Tudor, A., 2020, De ce digitalizarea in retail este mai importanta acum ca niciodata?, 5 octombrie, [online] Disponibil la retail-fmcg.ro/analyse/digitalizarea-onretail-html

Turpin, D.S., 2016, Trends that affect the future of marketing, November, [online] Disponibil la imd.org/research-knowledge/articles

Vazifehdoust, H.; Taleghani, M.; Eomaupour, F.; Nazari, K., 2013, Purchasing green becomes greener. Factors influence consumer green purchasing behavior, Management Science Letters, 3(9), September

Von Abrams, K.; Ceurvels, M., 2021, e-consumers in Europa will be more attuned to brand purpose and messaging, January 25, emarketer.com

Waide, M.; Bjerkan, H., 2020, Tree proactive response strategies to COVID-19 business challenge, MIT Sloane, April 17

*** Accenture COVID-19 consumer pulse research, June 2020

*** Consumer trends in the context of COVID-19, July 29, [online] Disponibil la one planetnetwork.org

Year XXIV no. 79

March 2021 
*** COVID-19 has change online shopping forever, survey shows, October 08 2020, unctad.org

*** COVID-19: How consumer behavior will be changed, April 28 2020, accenture.com

*** COVID-19 is reshaping consumer behavior, 2020, wabel.com/blog

*** COVID-19 is reshaping the consumer goals industry, 2020, accenture.com

***European Commission launches Green Consumption Pledge, first companies commit concrete actions toward greater sustainability, European Commission, January 25 2021, ec.europa.en

*** How has coronavirus changed consumer spending?, World Economic Forum, August 022020

*** Future of marketing: Digital of marketing the business world weapon after the COVID19, [online] Disponibil la www.scb.co.th

*** How COVID-19 is changing current and future digital behavior around the world, [online] Disponibil la kameleoon.com/en/blog/global-digital-studyCOVID-19

*** Responding to consumer trends in the new reality, KPMG International, November 2020, [online] Disponibil la home.kpmg/consumersnewreality

*** COVID19 pulse survey, November 2020, KPMG, [online] Disponbil la assets. $\mathrm{kpmg}$ (content)/dam $/ \mathrm{kpmg} / \mathrm{xx} / \mathrm{pdf} / 2020 / 11$

*** Top 7 home delivery innovations, springwise.com

*** 11/25 Update: The impact of coronavirus on consumer behavior, Numerator Intelligence, November 252020

*** Why sustainable consumption will be the new post-coronavirus normal, [online] Disponibil la telegraph.co/uk/search-marketing 